\title{
EL TEJEDOR: UN CASO DE CÁNCER METASTÁSICO EN LA HUACA POTOSÍ, VALLE BAJO DEL RÍMAC
}

\author{
ARELí SULLCA \\ UNIVERSIDAd NACIONAL FEDERICO VILLARREAL \\ areli1_5@hotmail.com \\ JOHNNY TAIRA \\ UNIVERSIDAD NACIONAL FEDERICO VILLARREAL \\ jota_1891@hotmail.com
}

AlfREdo Altamirano

Universidad Nacional Mayor de SAn Marcos / Universidad Nacional Federico VilLarReal. zooarqueologo@hotmail.com

\section{RESUMEN}

En el año 2003 se llevó a cabo excavaciones en los montículos 18 y 19 del complejo Maranga, valle del Rímac, a cargo de la arqueóloga Carmen Gabe. Durante esta excavación se halló en la Plataforma 2 norte del montículo 19 un contexto funerario de 5 entierros. Posteriormente, se realizó el desenfardo de uno de estos entierros, el cual correspondía a un tejedor, sin embargo, debido a características, tanto físicas (rasgos patológicos) como en su ajuar funerario, es muy posible que se esté tratando de un individuo que gozaba de un estatus social elevado dentro de su sociedad. El presente artículo es el resultado de un análisis Bioarqueológico de este caso y que dio como resultado patológico una severa lesión de cáncer metastasico, por lo que correspondería a uno de los pocos descubiertos en el área de Lima durante el periodo Horizonte Tardío.

Palabras Claves: Huaca Potosí, Maranga, entierro Ychsma, paleopatología, cáncer metastásico.

\section{ABSTRACT}

In 2003 conducted excavations in the mounds 18 and 19 complex Maranga, Rimac Valley, by archaeologist Carmen Gabe. During this excavation was found in the two northern platform mound 19 a funeral context 5 burials. Subsequently, desenfardo one of these burials, which corresponded to a weaver was performed, however, due to the features, both physical (pathological features) and its grave goods, It is likely being treated for an individual who enjoyed a high social status within their society. This article is the result of a bioarchaeological analysis of this case and that led to a severe 
injury pathological outcome of metastatic cancer, which would correspond to one of the few found in the Lima area during the Late Horizon period.

KeYwoRDs: Huaca Potosí, Maranga, burial Ychsma, paleopathology, metastatic cáncer.

\section{Investigaciones en Maranga y Huaca Potosí}

El Valle del río Rímac fue uno de los escenarios principales para el desenvolvimiento de las sociedades humanas precolombinas debido a la tecnología hidráulica de canales y organización social del Ayni. Aquí se desarrolló la población que habitó el complejo arqueológico Maranga, denominado así a la cultura pre-Tiahuanaco que habitó el valle de Rímac. Este se encuentra ubicado en la margen izquierda del Valle bajo del rio Rímac, a muy pocos kilómetros del litoral, lo que conllevó que fuera una sociedad dedicada a la pesca y al culto al mar, evidencia que se encuentra plasmada en la iconografía de su cerámica, textilería y demás manifestaciones culturales materiales. El complejo Maranga se encuentra conformado por una serie de montículos, algunos de ellos pirámides escalonadas, que datan desde fines del periodo Horizonte Temprano hasta el Horizonte Tardío (Figura 1), perteneciendo la mayoría de los edificios monumentales al Intermedio Temprano. El desarrollo y crecimiento urbano desordenado ha afectado a muchos de estos montículos, llegando a seccionarlos e incluso a desaparecerlos, permaneciendo en pie solo aquellos que por su relativo gran tamaño no han podido ser aplanados para servir como tierra de cultivo o vivienda.

Los primeros reportes sobre Maranga se dieron desde la segunda mitad del siglo XIX, viajeros como Georges Squier, Thomas Hutchinson y Ernst Middendorf, realizaron descripciones de estos montículos, especialmente de este último, ya que gracias a él se tiene las primeras descripciones detalladas, así como gráficos y fotografías del complejo Maranga (Hutchinson 1873, Middendorf 1973, Squier 1974). Middendorf logra identificar sectores urbanísticos, llamándole mucho la atención un sector amurallado que considera como el centro de la urbe. Posteriormente, investigadores como Uhle (quien nombra a esta cultura como proto- Lima). Villar Córdoba (1935) y Tello (1999) realizan pequeñas investigaciones en el complejo; en el caso de Villar Córdoba, analiza las toponimias y nombres de los sitios, con un posible origen Aymara. Tello hace un registro del complejo, describe algunos montículos como la Huaca Concha, Cinco Cerros (Mateo Salado), Aramburú o San Marcos, entre otros, llega a tomar fotos y dibujar planos de algunos sectores. Logra identificar murallas, caminos y 3 barrios, denominando a toda esta zona como Watika-marka.

Especial atención tienen Alfred Kroeber y Jacinto Jijón y Caamaño, ya que estos dos científicos son los primeros en intervenir el complejo Maranga, llevando a cabo excavaciones y planteando teorías sobre las costumbres y demás manifestaciones de la población que habitaba. En 1925 Kroeber realizó excavaciones en las huacas Middendorf y San Marcos, abriendo numerosos cortes exploratorios y trincheras, sin embargo no llegó a publicar sus resultados hasta muchos años después. Propone que los montículos correspondían a un periodo anterior a una supuesta expansión Tiahuanaco y correspondería al Proto-Lima planteado por Uhle (Kroeber 1954).

Por otro lado, Jijón y Caamaño realizó excavaciones en las Huacas San Marcos, Concha y Middendorf, en el mismo año que Kroeber, descubriendo numerosos entierros humanos, así como piezas de cerámica de diverso tipo asociados a las tumbas y rellenos arquitectónicos; entre sus hallazgos llama la atención el descubrimiento de una balsa de totora de unos 7 metros aprox. Propone que los montículos corresponden a la cultura Proto-Lima y se encontraba constituido por una aristocracia guerrera que había llegado al valle, conquistando e imponiéndose a los pobladores originales. Los hallazgos de huesos trabajados, entierros incompletos y mutilados hizo que se planteara que la sociedad Lima era un pueblo sanguinario que practicaba ritos sangrientos y crueles. (Jijón y Caamaño 1949) 
Arelí Sullca, Johnny Taira y Alfredo Altamirano / El Tejedor: Un caso de cáncer metastásico en la Huaca Potosí...

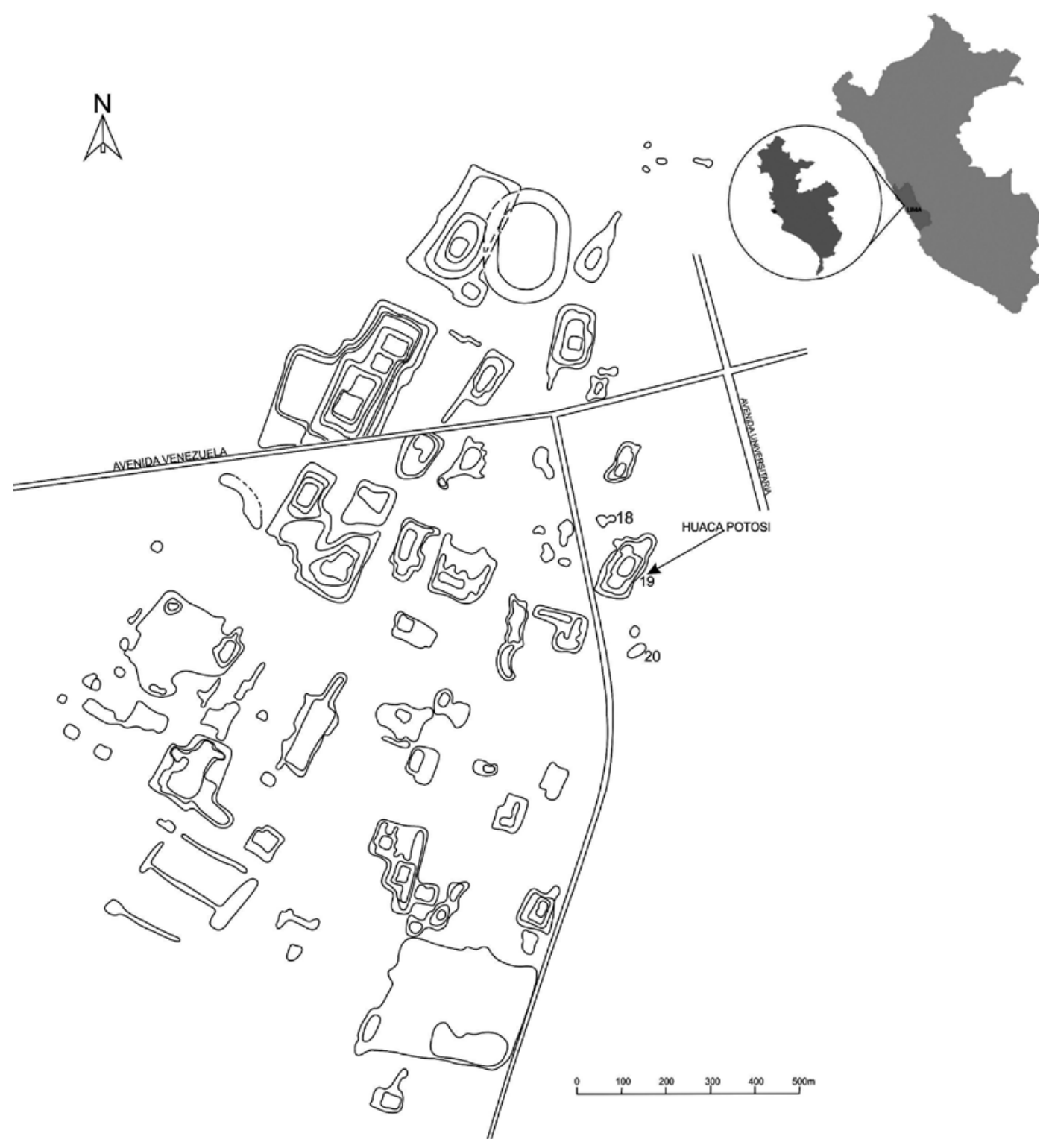

Figura 1. Plano del complejo arqueológico Maranga. Las líneas punteadas indican las secciones desaparecidas (Redibujado de Espinoza 2010: 266) 
Posteriormente muchas fueron las investigaciones en el complejo (Jaime 1999; Narváez 1999; Shady y Narváez 1999 y 2000; Mack kay y Santa Cruz 2000; Fung 2004: 297-308), de los cuales resaltan las de Pedro Alarcón, quien planteó la secuencia constructiva Lima basándose en las excavaciones realizadas en la huaca San Marcos (Alarcón 1971), y la de José Canziani, que realizó un estudio de la disposición urbana de los sectores Maranga (Canziani 1987 y 2008). Sin embargo, las principales y las de mayor aporte por su constante investigación, son las llevadas a cabo por el Patronato del Parque de las Leyendas y su museo de sitio Ernst Middendorf, ya que aquí se encuentra la mayoría de montículos del complejo Maranga (Carrión y Espinoza 2007a y 2007b; Manrique 2011 y 2012).

Las investigaciones etnohistóricas no son ajenas al complejo Maranga, María Rostworowski establece la existencia del señorío de Maranga al estudiar el cuaderno de visita de 1549. En este manuscrito se menciona la existencia de este curacazgo, que estaba dirigida por Juan Chayavilca, curaca de dicha región. Los visitadores refieren que los pobladores tenían acceso a los recursos del mar y realizaban intercambio con otros señoríos como Yauyos y Colli; sobre el origen de la población se menciona que es posible que sean mitmaq norteños traídos hasta el lugar debido a una sublevación del Chimu Capac hacia el imperio Inca (Rostworowski 1978: 88-97).

En el 2003 se llevó a cabo el Proyecto de Investigación Arqueológica “Excavación con fines de consolidación, conservación, mantenimiento y Puesta en Valor en el Complejo Arqueológico Pando: Potosí, Miguel Grau, Aramburu. Distrito de San Miguel, Provincia de Lima", dirigida por Carmen Gabe, en este proyecto se excavaron los montículos 18 y 19, los cuales forman el complejo arqueológico de Potosí Alto.

El montículo 18 es un pequeño promontorio sin estructuras visibles en su superficie, presenta una forma irregular debido a las múltiples mutilaciones sufridas durante la urbanización de la zona. Tiene aproximadamente 2 metros de altura y unos $70 \mathrm{~m}$ de extensión aprox. La primeras investigaciones en este montículo se llevó a cabo en la década de los 70', por la arqueóloga Martha Belcore (Belcore 1970), de este trabajo no existe mucha información disponible, solamente se resalta el hallazgo de una figurina de $40 \mathrm{~cm}$ de altura, representando a un personaje con los brazos extendidos. Esta figurina de filiación Chancay tiene la particularidad de presentar una cocción en atmósfera reducida. Presumiblemente habría sido hallado en la parte superior del montículo, es decir de las estructuras asociadas a la segunda etapa constructiva, la cual se presume del período Intermedio Tardío.

En la investigación del 2003 se pudo determinar que existieron 4 fases de ocupación que va desde el Intermedio Temprano hasta el Intermedio Tardío, cada una de estas fases presenta un patrón constructivo propio (Figura 2). La primera fase está representada por muros hechos con adobitos unidos con barro y usando la técnica "del librero", esta fase pertenece a la cultura Lima; la segunda se encuentra representada por muros hechos en base a cantos rodados unidos con barro, que formaban lo que parece ser una plaza; la tercera fase corresponde a la construcción de estructuras circulares y cuadrangulares, denominadas cámaras y se encuentran ubicadas en la parte superior del montículo, por último, la cuarta fase corresponde a cistas ubicadas en el extremo suroeste del montículo, poseen forma cuadrangular y están hechas con adobe, esta última fase correspondería al Intermedio Tardío y se está usando como cementerio (Ccachura 2010).

El sitio montículo 19 está compuesto por 3 plataformas o niveles, lo que origina que tenga una forma de pirámide escalonada, tiene una altura de $9 \mathrm{~m}$. y un largo máximo de $100 \mathrm{~m}$ aprox.. Este montículo se asocia a un conjunto de estructuras pequeñas hechas de adobitos que se ubican en el lado norte y presenta una orientación hacia el Noreste. 
La primera intervención arqueológica en el sitio se llevó a cabo en el año de 1990 y 1991 por la arqueológica Sonia Quiroz, quién realizó excavaciones de prospección en el montículo principal (Montículo 19 o Potosí), el objetivo principal de su excavación era definir la secuencia cultural interna (Quiroz 1992), es así que seleccionó 2 sectores (I y II) de los cuales pudo identificar ocupación Lima y Republicana en el sector I, mientras que en el sector II encontró estructuras hechas con adobitos paralelepípedos y cuadrangulares, construidos con la "técnica a" planteada por Alarcón, definiendo que estas estructuras pertenecen a la última fase de la Cultura Lima.

En las investigaciones del año 2003 se excavó las 3 plataformas, con dicha intervención se pudo definir que en la Plataforma 2 sur, existen tres momentos de ocupación. En la plataforma 2 norte se encontró una serie de remodelaciones, tanto en la arquitectura como en el manejo del espacio,

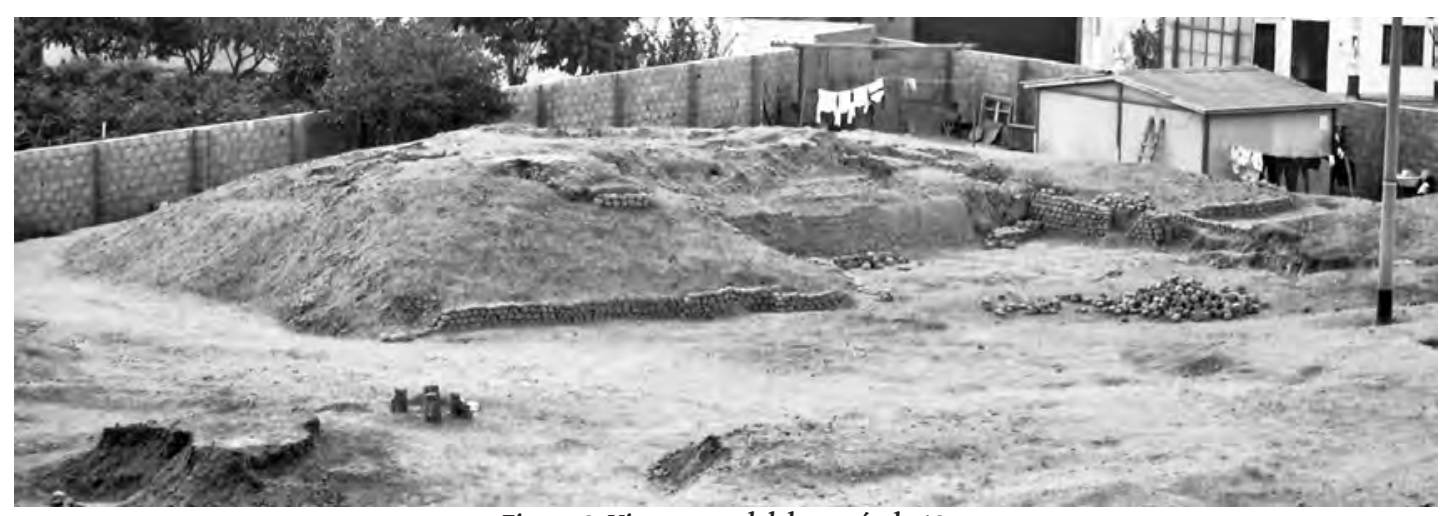

Figura 2. Vista general del montículo 18.

muchos de los recintos fueron reutilizados como cementerio. Se halló varios entierros, que pertenecerían a las últimas fases del Horizonte Medio e inicios del Intermedio Tardío, muy posiblemente al Ychsma Medio.

En la plataforma 3 se puede distinguir 4 secuencias de ocupación con sus respectivas remodelaciones. Aquí se halló un corredor delimitado con muros pintados de color ocre, este corredor presenta una rampa que va de sureste a noreste. En esta plataforma se encontró también una puerta in situ, asociado a un corredor y recinto pintado de color ocre amarillo (Taira y Sullca 2014).

\section{El Tejedor de Potosí}

En el año 2003 se llevó a cabo excavaciones en los montículos 18 y 19 del complejo Maranga a cargo de la arqueóloga Carmen Gabe, con el fin de ponerlo en valor, durante esta excavación, en la plataforma 2 Norte, se puso en evidencia un contexto funerario compuesto por 11 entierros ( 5 en un contexto y los 6 restantes distribuidos en 2 recintos funerarios), posteriormente en la etapa de gabinete nos llamó mucho la atención un fardo al que habían bautizado como "el tejedor" debido al ajuar funerario con el que fue encontrado, por lo que procedimos a desenfardarlo. Este fardo se encontraba cubierto con material de relleno, con una vara pegada al fardo en posición vertical y pertenecía a un contexto funerario compuesto por 5 entierros (fig. 3), de los cuales al "Tejedor" se le denominó como entierro $\mathrm{N}^{\circ} 1$ y se encontraba en el medio de estos 5 , cabe resaltar que este entierro era el único que contenía ofrendas, ya que los 4 fardos restantes ubicados a sus lados, no presentaban ofrenda alguna.

Las ofrendas estaban compuestas por una cerámica de cocción oxidante, la cual presenta una posible representación fitomorfa (lúcuma); un ejemplar muy parecido a esta cerámica fue encontrado 


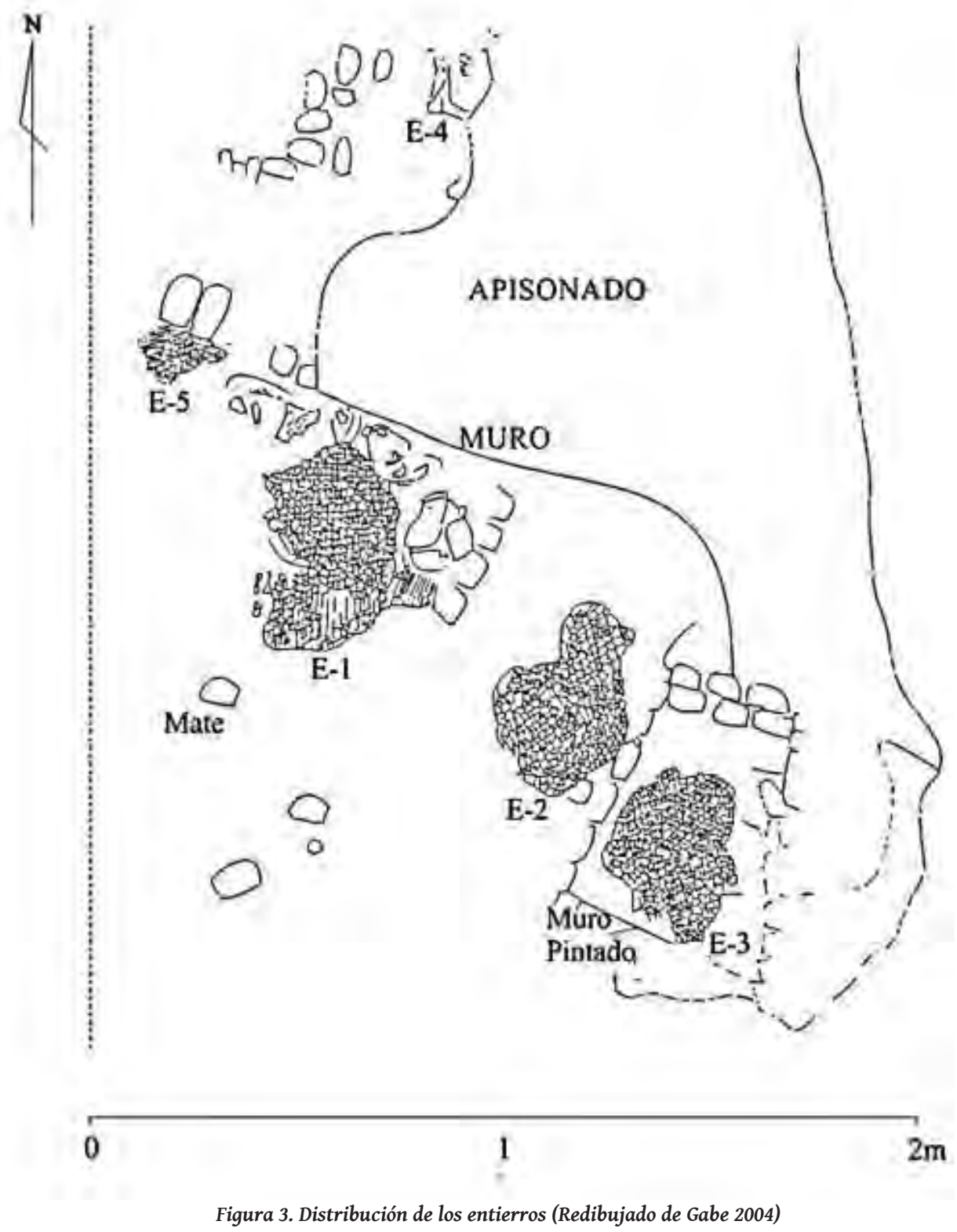

por Jijón y Caamaño durante sus excavaciones en el sitio denominado por el cómo Huaca I (Huaca San Marcos) en el entierro que denominó como TI-XXII (Lumbreras 2011: 307. Figura A, Jijón y Caamaño 1949 fig. 79), sin embargo a comparación del fardo del “Tejedor", este entierro era aparentemente modesto, pues se encontraba envuelto en una sola tela y contenía algunas vasijas con representación fitomorfa. 
Arelí Sullca, Johnny Taira y Alfredo Altamirano / El Tejedor: Un caso de cáncer metastásico en la Huaca Potosí...

También se encontró una cesta de fibra vegetal, la cual contenía en su interior un conjunto de 14 husos, estos presentaban diseños incisos de cruces y líneas, así como una figura antropomorfa, decorados con pintura roja, amarilla, negra y blanca, gracias a estos diseños se puede datar el fardo como perteneciente a finales del Intermedio Tardío o inicios del Horizonte Tardío, muy posiblemente perteneciente a la cultura Ychsma.

Reiss y Stübel durante sus excavaciones realizadas en la necrópolis de Ancón hallaron un fardo que contenía una cesta de fibra vegetal como ajuar funerario, en cuyo interior se encontraba 15 husos (Reiss y Stübel 1880-87, lám. 86), tanto la cesta como el diseño de los husos son muy similares a los encontrados en "el Tejedor". Posteriormente, Peter Kaulicke realiza un análisis de la obra de los alemanes, e indica que este contexto, al que pertenecía la cesta con los husos, son del periodo Horizonte Tardío (Kaulicke 1997: 62). Por su parte, Jijón y Caamaño identifica en sus excavaciones en Maranga, al igual que en Ancón, una cesta muy parecida a la descrita (Lumbreras 2011: 264), estos hallazgos estarían corroborando nuestra datación. Por último, como parte del ajuar se descubrió 6 platos de mate y un cráneo de un infante con una mandíbula de adulto, el cual posteriormente analizaremos.

El fardo presentaba una dimensión de $75 \times 58 \mathrm{~cm}$, con una altura de $33 \mathrm{~cm}$, este estaba compuesto por 3 capas de textiles. En la primera capa estaba compuesta por un textil con decoración en franjas de color verde y marrón, se encontró una serie de ofrendas que consisten en pedazos de algodón trabajado (no contiene semillas) atadas con un hilo; un cubito de un infante; un ovillo de hilo de color verde azulado, así como restos de algodón mezclado con retazos de textiles y vegetales (posiblemente hoja de coca). Asociado a estas ofrendas se halló el brazo del individuo, el cual se encontraba momificado, presentaba las uñas en buen estado de conservación y un pedazo de algodón atado con hilos cubrían su mano, llama la atención la presencia de un posible tatuaje en forma de rombos ubicado en su brazo.

La segunda capa estaba compuesta por un textil de color crema con decoración de franjas marrones, la cual estaba atada con una cuerda de fibra vegetal, esta cuerda a su vez ataba a uno de los extremos una vara de madera trabajada (esto se nota debido a que presenta una especie de pulido en el cuerpo y los bordes biselados), es muy posible que el fardo contenía 2 varas, uno a cada lado, sin embargo solo se conserva uno, esta evidencia de la segunda vara se puede notar en los restos de la cuerda que aún se conservan. Al retirar esta capa se notó que el individuo estaba envuelto con un colchón de algodón sin trabajar, a su vez debajo de este colchón se halló una serie de ofrendas que estaba compuesta por un puñado de raíces y ramas ubicadas a ambos extremos, así como 5 ovillos de hilos de color blanco.

Por último la capa 3 estaba compuesta por un textil sin decoración de color blanco que debido a los líquidos orgánicos del cuerpo o adipocira (¿sangre?), adquirió un color rojizo oscuro o marrón, el cual estaba atado por la mitad por una especie de faja, el cuerpo del individuo se encontraba debajo de esta capa. Los restos óseos del individuo se encontraban desarticulado, sin embargo debido a sus extremidades inferiores que se encontraban momificadas se puede deducir que este presentaba originalmente una posición fetal, con las extremidades inferiores y superiores flexionadas.

Llama la atención la posición y el estado del individuo, ya que a este le faltaban los brazos (un brazo se encontraba como ofrenda) y el cráneo, por otro lado, el tronco del cuerpo, no coincidía con la posición original, ya que se encontraba transverso a las extremidades inferiores (Figura 4), todo esto, sumado a la gran cantidad de tierra, nos indicaría que se podría estar tratando de un re-entierro o entierro secundario (Sullca y Taira 2014). 


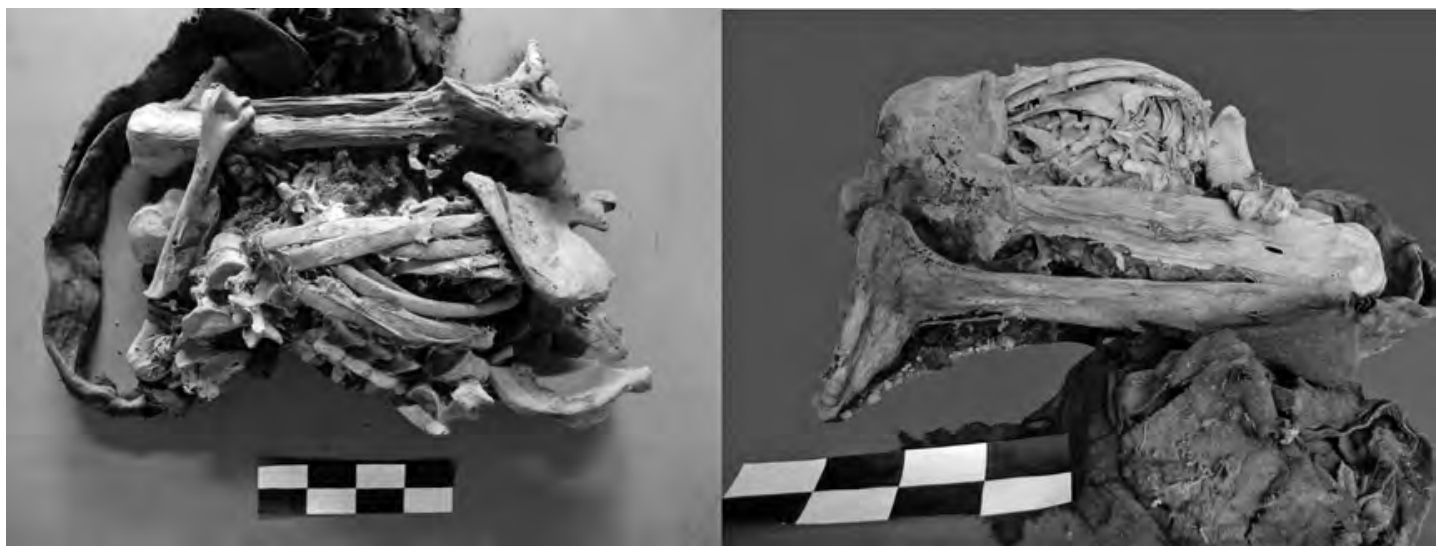

Figura 4. Posición original del entierro secundario.

\section{Análisis Paleopatológico del Caso}

El individuo encontrado en el fardo, al que denominamos como "el tejedor", se encontraba con partes óseas faltantes (brazo derecho, cráneo y algunas vertebras), por lo que se optó como metodología el análisis de cada parte ósea por independiente, para luego contrastarlo con los resultados y llegar a un cuadro clínico final que nos pueda indicar la causa de muerte, actividades en vida y patologías sufridas en vida.

La extremidad inferior derecha se encontraba momificada conservando la piel hasta la parte del fémur. Se pudo identificar un osteosarcoma en la epífisis proximal del femur, la cual se expande por todo el cuello anatómico, así como parte del trocánter menor y mayor (figura 5). En algunas costillas se puede identificar lesiones líticas las cuales se localizan en la cabeza, a su vez, estas lesiones pueden estar relacionadas con la severa destrucción del cuerpo vertebral de algunas vértebras Lumbares y torácicas, las cuales también presentan espondilólisis (figuras 6 y 7).

Ambos húmeros presentan una perforación supracondilea y epífisis distal con hipervascularización, lo que nos demuestra que ejercía una gran actividad en los brazos, el húmero derecho sin embargo presenta una posible osteítis en la apófisis próximal, muy cerca a la cabeza del humero. El omoplato izquierdo presenta un área con lesiones líticas en la parte del ángulo superior, mientras que en la derecha se ubica en la cavidad glenoidea y en el borde medial. La clavícula derecha también presenta lesiones líticas pequeñas y grandes en el extremo acromial (figura 8).

El esternón se encuentra con la apófisis xifoides faltante, el mango presenta un posible corte perimortem en el lado izquierdo con lesión lítica, esta lesión también se puede notar en la escotadura articular.

El sacro presenta 3 perforaciones producto de lesiones líticas, la primera ubicada en la parte inferior del primer agujero sacro anterior, esta lesión mide 1.7 x $1.4 \mathrm{~cm}$ y penetra hasta el otro lado; la segunda lesión se ubica en la parte posterior de la aleta derecha del sacro, esta mide 2 × $2.2 \mathrm{~cm}$ y perfora casi por completo; la tercera lesión se ubica en la parte inferior del primer agujero sacro posterior, esta mide 0.5 x $0.7 \mathrm{~cm}$ y es la salida de la perforación causada por la lesión lítica ubicada en el lado anverso (figuras 9). Por último, el hueso coxal izquierdo presenta una perforación producto de una lesión lítica y posterior osteosarcoma ubicado en el pubis (figuras 10), por otro lado, el coxal derecho presenta porosidad también en la parte del pubis. 
Arelí Sullca, Johnny Taira y Alfredo Altamirano / El Tejedor: Un caso de cáncer metastásico en la Huaca Potosí...

El análisis de los restos óseos nos permite inferir que individuo presenta una severa patología de destrucción ósea generalizada y cuyas diversas ubicaciones nos conducen a inferir que estamos frente a un caso de cáncer metastásico.

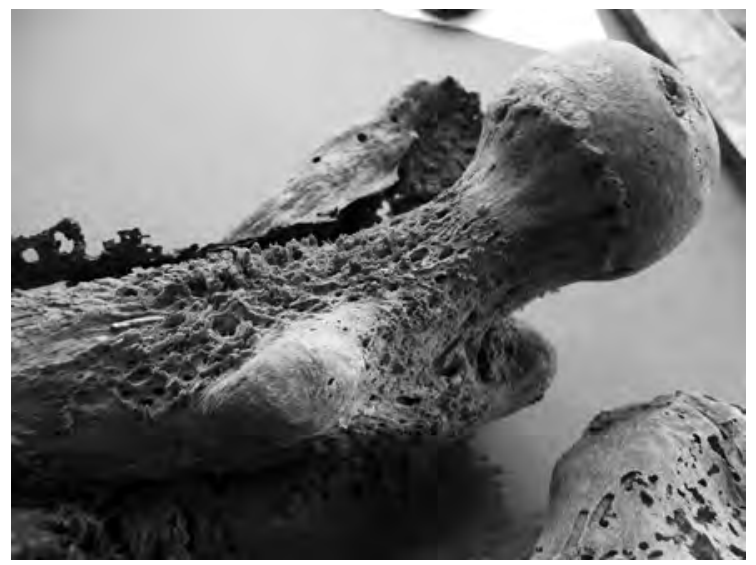

Figura 5. Osteosarcoma ubicado en el fémur derecho del individuo.

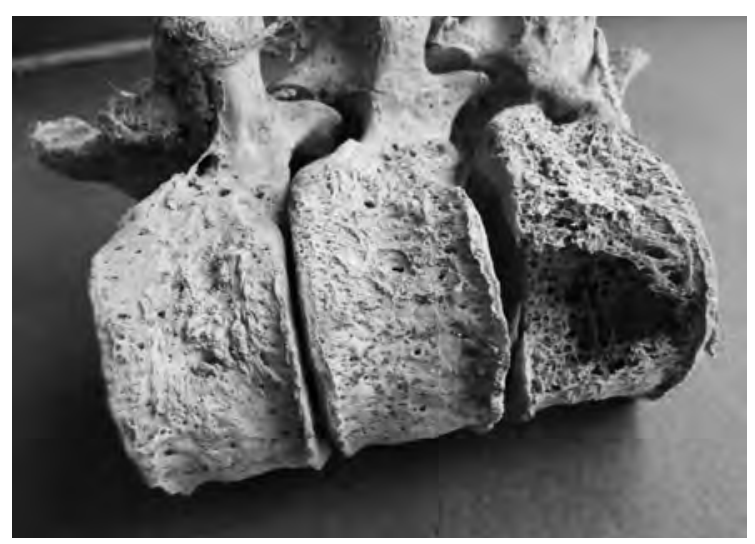

Figura 7. Vertebras del individuo con evidencia de espondilólisis $y$ destrucción del cuerpo vertebral.

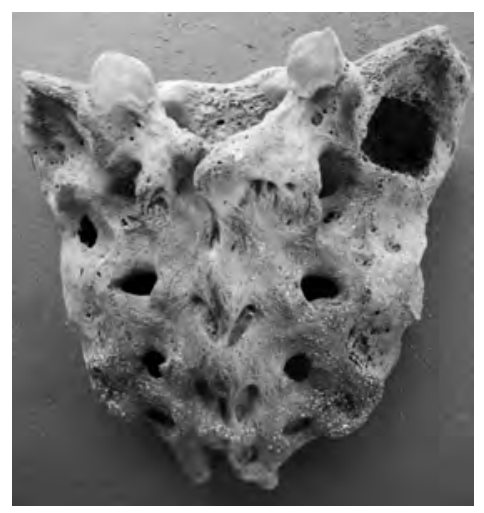

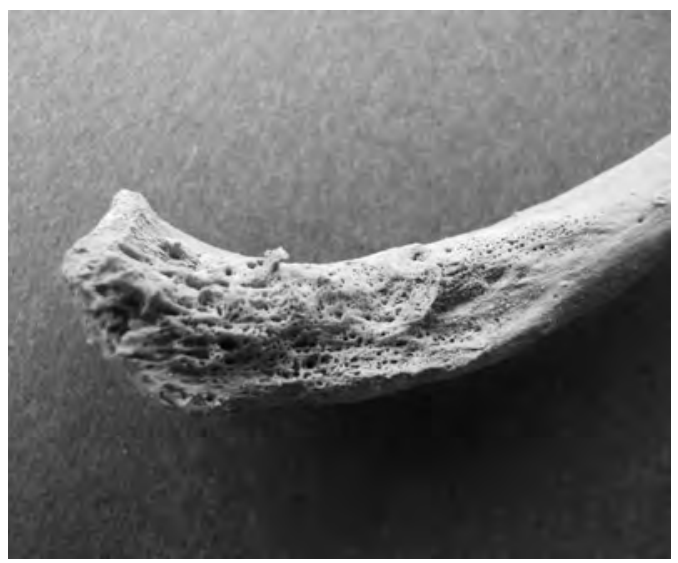

Figura 6. Lesión lítica en la cabeza de la costilla.

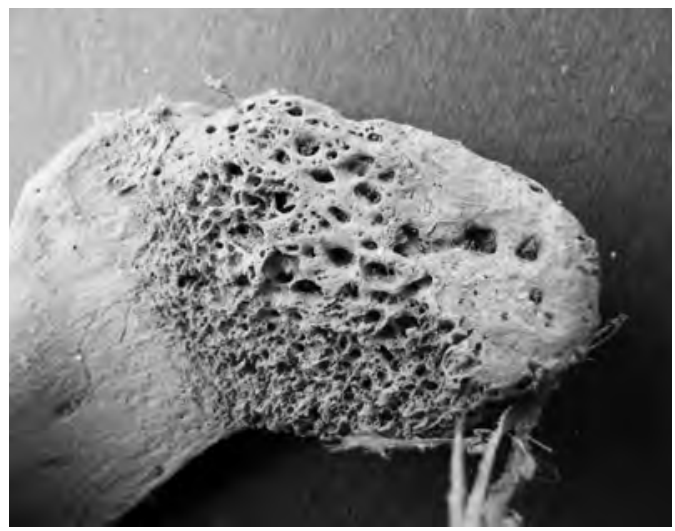

Figura 8. Lesión lítica en el extremo acromial de la clavícula.

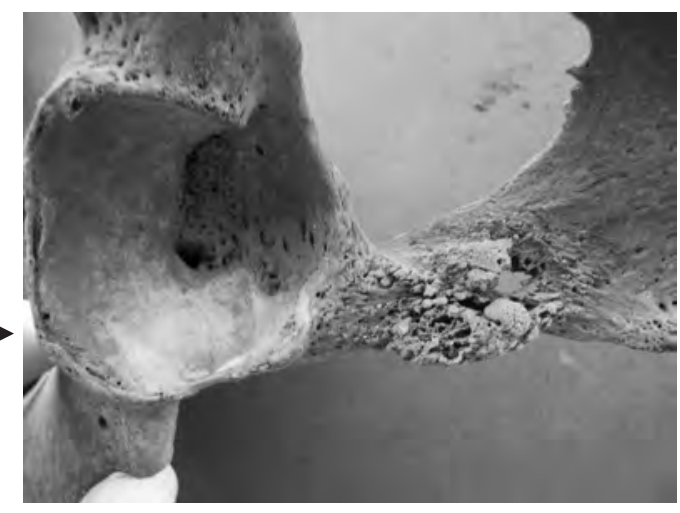




\section{ANÁlisis del Niño Sacrificado Y La OfRenda ÓsEa}

La ofrenda ósea estaba compuesta por un cráneo y una mandíbula, ambos eran de diferentes individuos. El cráneo presentaba una deformación cefálica de tipo tabular erecta (Weiss 1961, 2000; Munizaga 1987), esto se conseguía mediante el uso de un aparato deformador que ejercía presión en el cráneo, este aparato se denomina cuna. La deformación se caracteriza por presentar la parte superior de la escama del occipital aplanado y con dirección perpendicular al plano auriculo-orbitario. Tanto Weiss como Munizaga señalan que este tipo de deformación es típica de la costa central.

Se pudo identificar la edad del individuo del cráneo en base a la formación de la dentadura (Schour y Massler 1941), por lo que se estimó una edad aproximada de 4 a 5 años aprox. Presentaba el cráneo desarticulado (figura 11), el cual presenta un golpe perimortem en el hueso parietal izquierdo, muy cerca a la sutura sagital (figura 12). Por la huella del impacto dejado por el golpe, el cual presenta una forma oval, se descubrió que fue realizada con una porra circular, por lo que este infante seria la ofrenda de un posible ritual de sacrificio, cabe mencionar que los restos óseos (cúbito y falanges) encontrados en el fardo pueden pertenecer a este infante.

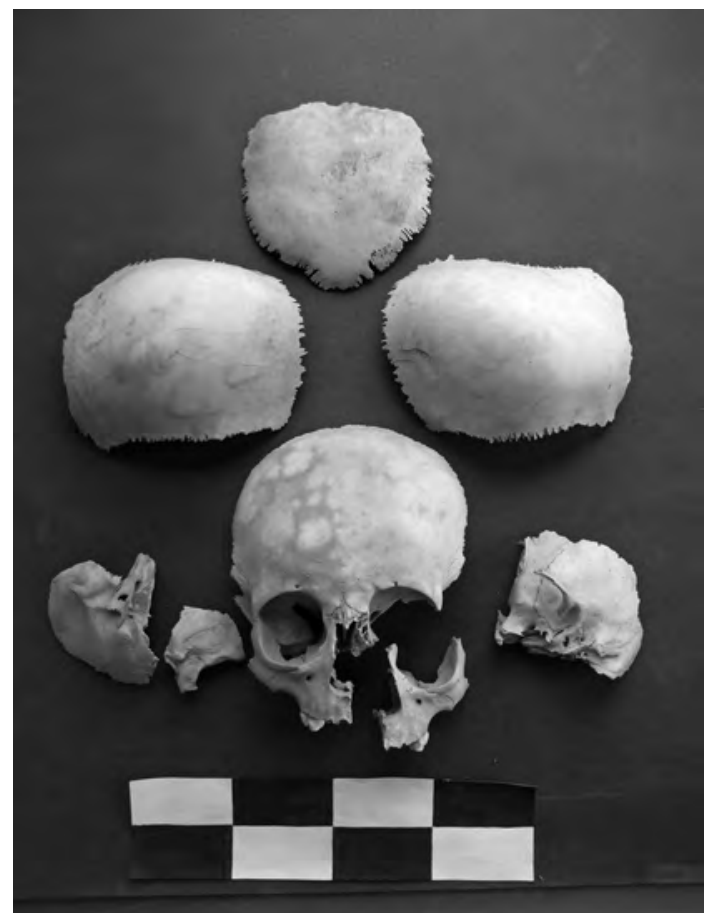

Figura 11. Cráneo de infante puesto como ofrenda del "tejedor".

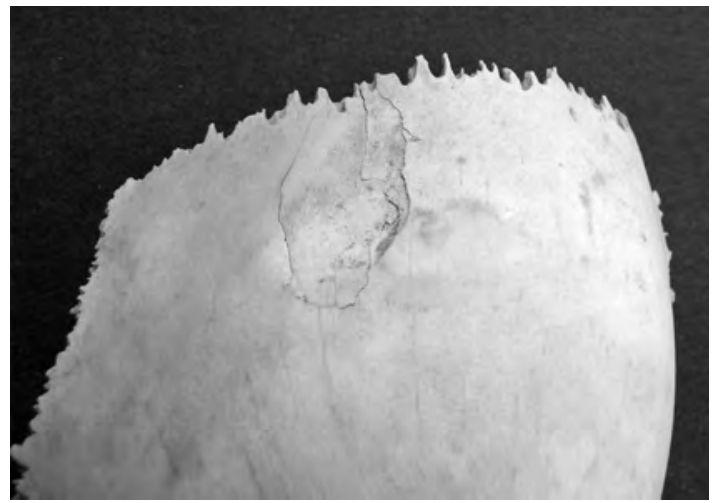

Figura 12. Trauma perimortem hallado en el cráneo de infante, producto de impacto de porra.

La mandíbula hallada como parte de la ofrenda pertenece a un individuo adulto y de sexo masculino, los molares se encuentran perdidos y obliterados, mientras que el segundo premolar derecho está con un desgaste dentario fuerte, presenta caries y una infección muy fuerte en este diente (Fig.13). También se encuentran perdidos y obliterados el primer incisivo de ambos lados (derecho e izquierdo), muy posiblemente fue intencional, el cual se realizó mediante un ritual para la colocación 
del tembetá (fig. 14), este adorno facial era un símbolo de masculinidad y de poder dentro de una comunidad o sociedad (Tello 1967). Se reportó un caso del uso de este objeto en el sitio arqueológico de Huallamarca para la época Lima (Carbonel 2013). Sin embargo, el individuo estudiado estaría perteneciendo a épocas tardías (Intermedio Tardío u Horizonte Tardío). Al comparar los restos óseos de la ofrenda con el individuo encontrado en el fardo se pudo identificar que la mandíbula pertenecería al individuo descubierto en el fardo ("el tejedor").

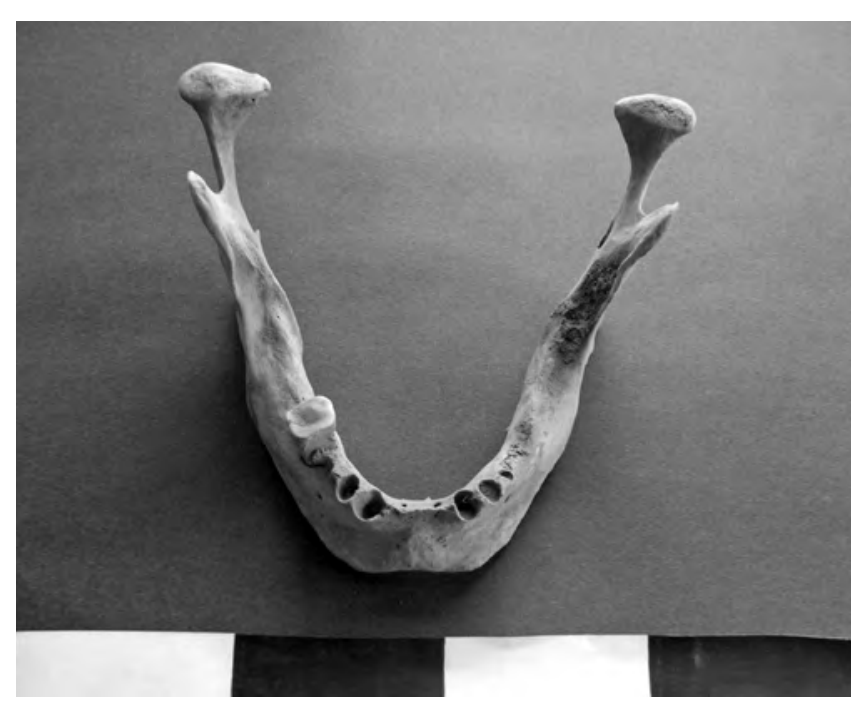

Figura 13. Mandíbula hallada como ofrenda, ausencia de dientes incisivos inferiores por uso de tembetá.

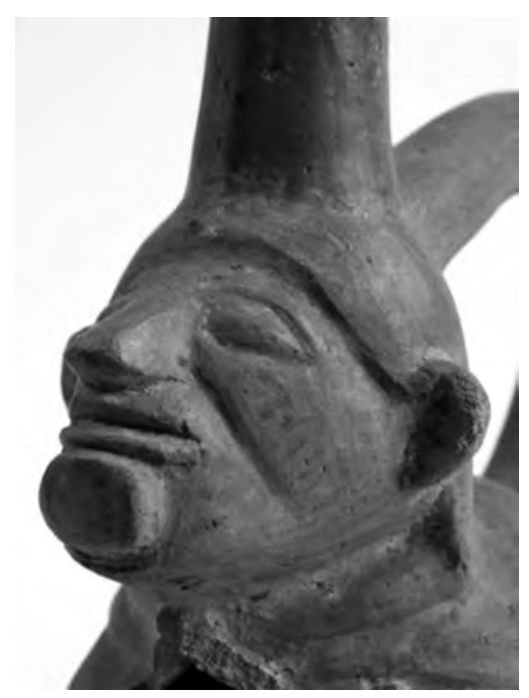

Figura 14. Cerámica moche con representación del tembetá.

\section{Diagnóstico Diferencial}

Siguiendo la metodología de Altamirano y Bueno (2013) para establecer el diagnóstico diferencial del presente caso, vamos a discutir los casos de mieloma múltiple, mielomatosis o melanoma (noma), osteoma, tuberculosis y carcinoma metastático. Concerniente a los tumores malignos que afectan severamente al hueso existen 3 grupos: mieloma múltiple, mielomatosis o melanoma y Carcinoma metastásico.

El primero es el más común tumor maligno que afecta al hueso. Este tumor es derivado principalmente de células hematopoyéticas de la médula del hueso. Afecta cerca del doble de veces en hombres que en mujeres con un pico de incidencia que afecta a individuos entre 40 y 60 años de edad. Algún tejido óseo de hueso trabecular que contiene médula hematopoyética puede comprometerse particularmente como en las costillas, vértebras, cráneo y pelvis. En casos severos puede afectar la epífisis proximal del húmero y del fémur (Ortner \& Putschar 1985; Aufderheide \& Rodríguez-Martín 1998). En los casos de mieloma, los huesos afectados carecen totalmente de remodelación ósea y un contraste para la forma irregular de orificios y apoyando frentes del hueso cortical aislado y "reabsorción", aglutinándose en la confluencia y "superficie de campo de golf". Las lesiones líticas presentan formas redondas grandes, irregulares y altamente destructivas, y no existe regeneración de tejido óseo adyacente a las lesiones. Es decir, no presenta reacción ósea periosteal. Esta enfermedad es más frecuente en individuos viejos (especialmente después de 50 años de edad), afectando en porcentajes iguales tanto a hombres como mujeres. 
La evidencia de mieloma múltiple es muy característica con presencia de numerosas lesiones líticas o perforaciones óseas circulares, pequeñas y difusas que varían entre 5 a $50 \mathrm{~mm}$ de diámetro con fuerte esclerosis de los huesos adyacentes a la lesión y a veces está conspicuamente ausente. Zimmerman \& Kelley (1982) y Rotshchild et al. (1998) observaron el caso de un esqueleto completo de hombre blanco de 50 años de edad ${ }^{1}$. El cráneo de este individuo presenta lesiones líticas de mieloma múltiple y cuyas características macroscópicas son perforaciones esferoidales, de bordes suaves y orificios de entrada y salida. Las pequeñas cavidades extensivas se encuentran en las costillas, omóplato, espina o columna vertebral, pelvis y sacro. En cambio, en casos de mieloma solitario es imposible el diagnóstico definitivo en restos de esqueleto seco. Además, si las lesiones son grandes, variadas y con espículas, un diagnóstico alternativo de carcinoma metastásico puede ser considerado.

El cáncer metastásico constituye el segundo de los tumores malignos que compromete seriamente los huesos. Carcinomas de mama, próstata, recto, tireoide, riñón y pulmón son particularmente propensos a la metástasis de hueso (Aufderheide \& Rodríguez-Martín 1998). Más específicamente, el cáncer colon-rectal produce una respuesta osteoblástica, destruyendo al sacro y pelvis con mayor intensidad; el cáncer mamario resulta tanto en lesiones líticas como osteoblásticas, y los casos del riñón, pulmón y tireoide producen generalmente lesiones osteolíticas. En muchos casos, en el centro esquelético de las metástasis se encuentra alrededor del órgano canceroso en cuestión (por ejemplo, pelvis, sacro y vértebras lumbares comprometiendo por carcinoma de próstata o del recto). Asimismo, las regiones esqueléticas más susceptibles son la columna vertebral, pelvis, costillas, proximal de húmero, fémur y el calvario (Zimmerman \& Kelley 1982).

Los llamados cánceres benignos u osteomas exponen generalmente el crecimiento de un callo óseo de forma ovoide, pequeña y tuberosa. Estas formaciones han sido observadas en la serie de Makat-tampu, como en los casos C-25 y C-29 y ambos son varones adultos. El primero tiene 40-50 años de edad y el otro de 35-40 años de edad (Altamirano 2000). Sin embargo, en este sitio arqueológico del Rímac hasta la fecha no se han detectado casos de mieloma múltiple. Asimismo, en los casos de leucemia, la relatividad de pequeños forámenes circulares y "frentes de reabsorción" son diferentes de aquellas lesiones de "espacio-ocupado" por mieloma múltiple. El tamaño uniforme de las perforaciones líticas es una característica tradicionalmente atribuida a mieloma múltiple. Ejemplos de lesiones de tamaño uniforme son indicadores de cáncer metastáticos, en cambio, lesiones de tamaño variable están relacionadas a individuos con mieloma múltiple. Estos datos indican una certeza en el uso del tamaño de las porosidades y su distribución para el diagnóstico diferencial (Zimmerman \& Kelley 1982; Rothschild et al. 1998).

Concerniente a la "artritis tuberculosa", las primeras evidencias óseas humanas ocurren en los Estados Unidos, México y Perú, lo que indican su presencia temprana en las Américas. En el vocabulario quechua se designa con la voz Chaque-oncoy, Chullu-oncoy o sucyay-oncoy (Lastres \& Cabieses 1959). Esta infección afecta principalmente a la espina dorsal, denominada el mal de Pott, destruyendo los cuerpos interiores de las vértebras torácicas y lumbares, formando lesiones líticas profundas o kyposis con reabsorción ósea y diseminándose luego a las costillas, esternón y la cadera -psoas- y es causada por el bacilo Mycobacterium tuberculosis (Moodie 1923, Buikstra 1980, Lombardi 1994).

Ortner (1992) describe un cráneo masculino de 15 años de edad que tuvo TBC desde los 5 años. Observó que estaba comprometido la estructura naso-maxilar, destruyendo los huesos nasal, cornetes,

1. Este individuo proviene de la colección Terry, esqueleto $\mathrm{N}^{\circ} 787$, procedente de St. Louis, Missouri y cuenta con 1600 individuos. Se encuentra depositado en el National Museum of Natural History, Smithsonian Institution, USNM, Washington, D.C. 
septum nasal, maxilar y paladar. Además, afectó la dentición total superior y cuyos alveolos habían obliterado. Tanto la cavidad nasal como la oral exhiben lesiones profundas con ausencia reacción ósea periosteal. Este caso se encuentra en el Museo de Patología del Royal College of Surgeons of Edinburgh, Escocia. Altamirano (2000) ha reportado en el cementerio de Ancón, período Chancay, el caso C-38 y en Huarochiri el caso C-36 con tuberculosis. Estos cráneos presentan 2 áreas de lesiones líticas. Una en el arco superciliar derecho del frontal, que se extiende desde la sutura naso-frontal derecho, alrededor de la órbita derecha hasta la eminencia lateral frontal derecha ( 45 x $33 \mathrm{~mm}$.) y otra en el occipital lado izquierdo (30 x $26 \mathrm{~mm}$ ) próximo a la sutura lambdática. El reborde de la lesión es irregular de aspecto gomoso, poroso, irregular y neoformación ósea. Esta superficie craneal expone escarificación, sin perforación total y con reabsorción ósea. Siendo diferente de cáncer metastásico por el tipo de reborde irregular y presenta una reabsorción ósea uniforme. Actualmente, las historias clínicas reportan que la TBC esqueletal se manifiesta en aproximadamente $1 \%$ de todos los casos, en cambio en el pasado, según Zimmerman \& Kelley (1982) durante la era pre-antibiótica, la prevalencia era alta entre 5-7\%. En el antiguo Perú ocasionaba múltiples problemas en la salud pública y arrasaba con aldeas enteras junto con la neumonía (Allison, Mendoza \& Pezzia 1973).

Se define como neoplasma ("nuevo crecimiento") o condiciones neoplásicas a una masa de tejido localizado. Su crecimiento es una respuesta de la proliferación celular, aparentemente normal y desajustada de los mecanismos de regulación. El grado de crecimiento autónomo empleado por algún neoplasma puede variar ampliamente. En algunos casos, tales como el común botón óseo (osteo$\mathrm{ma})$, los restos de neoplasma subyacen en la mayoría por el crecimiento, regulando conjuntos en el cuerpo, y formas solamente de una pequeña masa de tejido que es incapaz de destruir otras células próximas o migrando a otras partes del cuerpo. Tal comportamiento es considerado de carácter benigno. Otros neoplasmas que escapan a las restricciones fisiológicas son capaces de destruir tejidos normales próximos y células de ellos pueden afectar otras áreas del cuerpo vía vasos sanguíneos o linfáticos, estableciendo nuevos crecimientos (metástasis) en nuevos locales, tal comportamiento es descrito como maligno y el género de tales neoplasmas es llamado cáncer. Mientras que los términos benigno y maligno son productos de nuestras limitaciones terapéuticas modernas, y mientras que muchos neoplasmas humanos son subjetivos a incluir numerosos ejemplos de diferentes grados de crecimiento autónomo intermediario que incluyen estos dos términos. Sin embargo, la mayoría de los neoplasmas reflejan comportamiento estrechamente con reacciones óseas y remodelaciones en áreas de los extremos.

En el diagnóstico paleopatológico de tuberculosis, la columna vertebral es el área más propensa de infección, principalmente la región tóraco-lumbar y causando lesiones líticas del cuerpo vertebral anterior. Además, esta se parece más a la osteomielitis piogénica y blastomicosis que al cáncer metastásico. En nuestro caso, existe fuerte diferencia patológica entre TBC y cáncer metastásico. Entonces, para el DD del caso del "tejedor de Potosi" está relacionado a los tumores malignos y lesiones son sugestivas de cáncer metastásico por osteosarcoma debido a la fuerte destrucción ósea con reabsorción ósea periosteal. Por lo tanto estamos frente a un caso de cáncer metastasico cuya mayor intensidad y concentración se da en la pelvis y el sacro principalmente.

\section{El Cáncer en el Antiguo Perú}

Los estudios de neoplasma, neoplasia o cáncer son relativamente escasos en el registro arqueológico del orbe (Steinbock 1976, Ortner \& Putschar 1985, Roberts \& Manchester 1995, Aufderheide \& Rodríguez-Martín 1998, Verano \& Lombardi 1999). Para el caso andino, esta situación ha generado un debate en torno a que si los cánceres fueron raros en los períodos arqueológicos debido a la corta esperanza de vida o si hubo errores en el diagnóstico correcto de estas patologías. 
En el antiguo Perú se había considerado que la nutrición era buena y, por tanto, el ciclo de vida era largo. Así, un grupo de investigadores defendía que había una buena salud entre las antiguas poblaciones humanas de la costa central en los períodos tardíos, generando longevidad y que ultrapasaba los 50 años de edad (Horkheimer 1973; Antunez de Mayolo 1981; Espinoza 1990). Sin embargo, otro grupo de estudiosos, partiendo de la paleopatología y antropología física, afirmaron que la salud era precaria en tiempos tardíos, por lo que el ciclo de vida era corto, entre 30 a 40 años de edad, por tanto, no había tiempo para que el cáncer pudiera desarrollarse con mayor intensidad (Verano \& Lombardi 1999; Pechenkina et al. 2006, Chan 2011, Altamirano y Bueno 2013). Esta controversia ha generado una polémica poco tratada en los últimos dos lustros.

La segunda polémica concierne a los estudios de paleopatología antigua de Tello (1909), Hrdlicka (1914), Tello y Williams (1930), Lastres y Cabieses (1959) y Weiss (1984) para definir los casos de cáncer en huesos secos y arqueológicos, los comparaban con el material cerámico patológico. Estos destacados investigadores no utilizaron la radiografía (o raras veces) ni el diagnóstico diferencial, a pesar de su existencia desde inicios del siglo XX. Pues había confusión con casos de lesiones gomatosas de Tello, osteoporosis simétrica de Hrdlicka, hiperostosis porótica de Weiss y carencia de un consenso debido a la ausencia del método de la patología comparada, la paleoepidemiología y su discusión biomédica. Es decir, faltaba el puente metodológico y comparativo entre lo moderno y lo arqueológico tal como lo propone el enfoque Paleoepidemiológico. Por lo que los estudios de la epidemiología del cáncer recién comienzan a proliferar a partir de 1990. Otro problema es discernir sobre el origen del cáncer en nuestro caso. Sabemos que sobre su etiología existe una amplia gama de factores, tales como los genéticos, nutricionales, ecológicos y culturales. El cual escapa a nuestra investigación debido a la carencia de frecuencia de casos antiguos y su comparación con poblaciones actuales.

\section{LA HIPÓTESIS ETNOHISTÓRICA}

Diversos cronistas de los siglos XVI y XVII que vieron la caída del imperio Tawantinsuyu han descrito pasajes del "cáncer de los Andes". Ellos observaron con frecuencia en los antiguos peruanos, como agricultores, pastores, mineros y pescadores, el severo adelgazamiento, la postración, sus dramáticos síntomas e intensos dolores, que los conduciría irremediablemente a la muerte (Lastres \& Cabieses 1959: 278). En forma tangencial, se han ocupado de este tema Hrdlicka (1914), Mac Curdy (1923), Moodie (1923), Tello y Williams (1930), Lastres \& Cabieses (Op. Cit.) y Weiss (1984). Así, el cáncer estuvo presente desde tiempos remotos y las evidencias arqueológicas de tumores malignos primarios o metastáticos pueden comprobarse, sin lugar a dudas, en diversos cementerios autóctonos.

En quechua existe el término Yzco unccoy o Yzco uncuyniyoc que significa "muy canceroso" y, por extenso, Yzco unccoy hapihuan que denota a la persona portadora de cáncer. Desde el punto de vista filológico se admite que si se creó el término por tanto existió el mal en forma genérica. Esto quiere decir que los conocimientos empíricos de los médicos hampicamayoq no les permitieron diferenciarlos clínica ni específicamente el tipo de cáncer. Por otro lado se conocía a las enfermedades con nombres onomatopéyicos y desgarradores como uta, huanthi y Chaqueonccoy, estos corresponden a leishmaniasis, treponematosis y tuberculosis, respectivamente. Asimismo, también había remedios paliativos y curativos. Por lo que Antonio de La Calancha (1639) señala que los indios usaban "un género de conchuelas y una yerba mezclada lo uno y hecho emplasto lo otro para atajar el cáncer". De esto se desprende la hipótesis etnohistórica que indica que el cáncer andino era visto como un mal fatal que afectaba a individuos ancianos de la costa, sierra y selva, entendido dentro de la medicina tradicional por causas espirituales, en forma general y no específica. En la cosmovisión andina, este mal era considerado como el espíritu de las huacas o de las montañas sagradas que habían ingresado en el 
cuerpo del individuo, ahora enfermo, debido a transgresiones y faltas hechas a los seres sobrenaturales, carencia grave de ritual o "pago a la tierra" y a las normas de la naturaleza (Espinoza 1990: 170). Actualmente, los campesinos de Ayacucho, Apurímac, Huancavelica y Junín le denominan el "mal de Wari". o sea, el cáncer habría surgido por el desequilibrio biocultural del hombre con la naturaleza (es decir con sus dioses naturales como la pachamama, mamacocha, huancas, jirkas, cerros, etc.).

Para agobiar estos males y estreses, durante el Tawantinsuyu había una fiesta ceremonial llamada Capac Situa que ocurría en el mes de octubre y simbolizaba la época del culto a los ancestros, la purificación del espíritu y la limpieza de las enfermedades (Lastres 1951). Sobre este profundo sentimiento de religiosidad andina, Tello (1931) decía que los alfareros intercambiaban sus piezas periódicamente según el ritmo del calendario oficial agrícola, aludiendo diseños, temas, escenas y símbolos según el recuerdo del mito ceremonial. Y gracias a las representaciones de la cerámica y los tejidos estos mitos se mantuvieron latentes por siglos. En suma, para los cronistas hispanos, y muchos de ellos que no eran médicos, el término cáncer se usaba ampliamente para referirse a todas las enfermedades incurables que producían lesiones destructivas, deformantes y la muerte, incluyendo la leishmaniasis, hanseníasis, gangrenas, nomas, blastomicosis, sífilis, diversas dermatitis y tuberculosis, entre otras. Por tanto, había una gran confusión en la Colonia por la correcta definición del cáncer, además del fuerte dominio de la teoría miasmática, esta teoría consistía en que las enfermedades eran transmitidas por el contagio, por el aire, el agua y la comida putrefacta; por ejemplo, la emanación de los gases tóxicos de las minas se consideraba que producía la verruga peruana y la fiebre de la Oroya, y era consebida como 2 males diferentes; también se pensaba que sentir el aire de las huacas y cementerios producía paralisis facial, cáncer, epilepsia, etc. (Altamirano et al. 2003)

\section{LA HIPÓTESIS BIOMÉDICA}

En el Perú actual, la epidemiología y patología del cáncer en óbitos se puede organizar según los órganos afectados, siendo los casos más frecuentes los de estómago y esófago (80\%), próstata (60\%), pulmón (55\%), mama (40\%), vagina (35\%) y bazo e hígado (33\%). Sus causas pueden ser variadas como las espaciales que indican el asentamiento donde viven (como recibir intensa radiación, presencia de antenas de radio y TV y contaminación de minerales), los excesos de frituras, los malos hábitos, la sedentarización y hasta el tipo de agua que beben. Para los casos de estómago, esófago e intestinos se ha detectado a la bacteria Helicobacter pilori como el principal agente del inicio de la destrucción del tracto digestivo. La mayoría de las lesiones cancerígenas que afectan al esqueleto humano evolucionan a metástasis. López-Durán (1995) anotó que en ciertas personas, con más de 40 años de edad, comienzan a desarrollar algunos tumores malignos desde algún órgano enfermos, es decir, desde el cáncer primario hacia algún órgano distante, causando metástasis. Asimismo, algunos cánceres primarios son más aptos a metástasis ósea que otros. El más común de estos son los carcinomas prostáticos (70\% de estos compromete a la columna vertebral) y carcinoma de mama (30-50\%). Pulmón, riñones y tireoides son menos frecuentes. Desde aquellos puntos primarios ocurren frecuentemente en personas viejas, esto sigue a carcinoma metastático del hueso, por tanto, es ampliamente aceptada ser una enfermedad de la vejez.

Los huesos comúnmente más afectados son la pelvis, sacro, costillas, vértebras, principales huesos largos, esternón y cráneo. Esta lista de puntos óseos metástásicos refleja la distribución del hueso trabecular y los sistemas haversianos complejos donde se filtran la sangre. Por otro lado, las metástasis en los huesos de los codos y rodillas no son comunes (Thillaud 1996). Por tanto, las metástasis óseas son consecuencia de la diseminación hematógena tal como el caso del "tejedor". 
En el antiguo Perú se han reportado los siguientes casos de cáncer: Urteaga \& Pack (1966) que nos relatan un posible caso de melanoma en el Tawantinsuyu; Steinbock (1976) presenta dos casos de lesiones líticas en cráneos peruanos y dos más de Alaska; Allison (1980) muestra el caso de una mujer adulta peruana con lesiones líticas y osteoblásticas en el cráneo, pelvis y columna vertebral de la costa sur (¿cáncer de mama?); Baraybar y Shimada (1993) exponen otro caso de próstata en la costa norte, área de Lambayeque-Sicán, con lesiones porosas en las vértebras osteoblásticas; Peters, Cagigao y Lund (2011: 107) presentan el caso de un hombre adulto de 40-55 años de edad de la costa sur, Paracas Necrópolis de la fase Nasca I, con diagnóstico de cáncer metastásico, afectando principalmente el cráneo; por último, Altamirano y Bueno (2013) presentan un caso de un hombre adulto del Horizonte Medio con cáncer metastásico, producto de un cáncer de colon-recto.

En el orbe, la paleopatología del carcinoma metastásico ha reportado innumerables ejemplos en esqueletos antiguos. Estos incluyen a los de Hooton (1930) que describió dos casos de mujeres adultas de los Pueblos Pecos, EE.UU, envolviendo la columna vertebral, radios y cúbitos; Brothwell (1967) en la región de Saxon, Reino Unido, publica un caso con severas lesiones óseas; Manchester (1983) presenta el esqueleto de una anciana de Inglaterra que afectó su cráneo y fémures (¿cáncer de mama?); Tkocz y Bierring (1984) expone un hombre adulto medieval de Dinamarca que afectó la columna vertebral, pelvis y omoplato por lesiones osteoblásticas (¿próstata?); Waldron (1987) expone un caso del siglo XVIII que vivió en Inglaterra, era un anciano fuertemente destruido el cráneo, siendo su diagnóstico de cáncer de pulmón; Ortner et al. (1991), en Inglaterra, período Medieval, lesiones en huesos múltiples (¿pulmón?); Strouhal (1991), expone a un hombre adulto de Nubia del período Cristiano, que afectó la mandíbula, maxilar y huesos faciales (¿invasión primaria directa?); Anderson et al. (1992) publica otro caso de posible próstata del siglo XIV del Reino Unido, afectando costillas y cráneo. En suma, estos datos refieren a la escasez de casos de cáncer en la costa central durante los períodos tardíos y esto se debía a la carencia de investigaciones en este tema. Es muy posible que este mal fuera endémico en el pasado y confirmaría que el ciclo de vida del yunga era corto

\section{ConCLusiones}

Es muy posible que el fardo sea un re-entierro de este individuo, ya que se encontró varias de sus partes fuera del fardo (como ofrenda) y el individuo al interior de este se hallaba el cuerpo desarticulado y con partes óseas faltantes (brazo derecho, cráneo, algunas vertebras), así como con mucha tierra y basura (canto rodado, cerámica, malacológico, etc). Esta evidencia, sumada a la posición en el contexto funerario (fue el único de los 5 fardos que contenía ofrenda y se encontraba en el medio), nos podrían indicar su importancia y es posible que se estuviera practicando ritos religiosos (posible culto al ancestro), el cual es típico de las sociedades andinas, este consistía en sacar a "pasear" o realizar reuniones públicas en memoria y con la presencia del personaje fallecido (Dulanto 2002), sin embargo, esto se podría comprobar con estudios posteriores que consistirían en desenfardar los otros 4 entierros asociados para comprobar si fueron enterrados como ofrenda de este individuo, son parte de un posible linaje o pertenecen a contextos e individuos diferentes.

El análisis de los restos óseos nos brinda datos muy interesantes en cuanto a la vida y muerte del individuo del fardo ("el tejedor"). Este era un hombre de unos 30 a 50 años de edad aprox. La mandíbula encontrada en la ofrenda pertenecía a este individuo, la cual presenta una fuerte infección dentaria producto de una carie muy avanzada, lo que nos estaría indicando una dieta muy rica en carbohidratos, proteínas y grasas.

La presencia de un posible uso de tembetá nos demostraría un elevado estatus dentro de su sociedad, ya que dentro de la literatura antropológica, el uso de este artefacto está destinado a individuos 
que gozan de un rango elevado dentro de ciertas sociedades, la obtención de este objeto se logra luego de pasar diferentes pruebas rituales a los que son sometidos algunos niños al cumplir la mayoría de edad. Se halló también un tatuaje en forma de rombos ubicado en la mano derecha del individuo (fig. 15), la cual se encontró como ofrenda, el tatuaje dentro de las sociedades son usados como signo de estatus social, asociado a ritos de pasaje a la adultez o simplemente como una forma de embellecer el cuerpo, estos dibujos y símbolos impregnados en la piel sirven para identificar grupos sociales y culturales, es decir, son marcadores de identidad. Históricamente existe más pruebas del uso de tatuajes en sociedades costeras que en las poblaciones alto andinas (Allison et al. 1981).

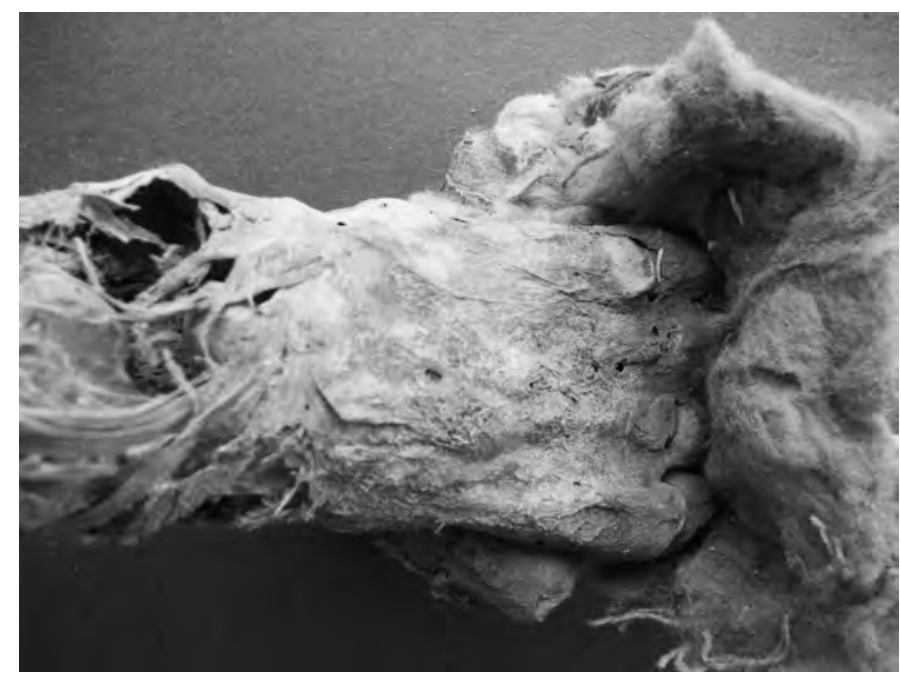

Figura 15. Tatuajes en forma de rombos ubicados en la mano derecha del individuo

La presencia de uñas en las manos y las patologías causadas por acciones de estrés repetitivo en el húmero (perforación supracondilio e hipervascularización), así como las ofrendas de hilo y artefactos de textileria, nos indican una función de tejedor del individuo cuando estaba vivo. Las vértebras axis y atlas no presentan huellas de corte, por lo que se descarta la posibilidad de una decapitación del individuo para explicar al falta del cráneo. La espondilólisis nos indicarían que el individuo estaría haciendo en vida trabajos de carga o donde se moviera la columna con mucha fuerza y constantemente.

Todas las articulaciones presentan lesiones líticas de tipo neoplásico (osteosarcoma y perforaciones cancerígenas), por lo que se trataría de un caso de cáncer metastásico producido por una posible leucemia o cáncer de próstata. Por otro lado la presencia de un corte perimortem en el lado izquierdo del mango del esternón, nos indicarían que posiblemente al individuo lo apuñalaron en el pecho con un objeto filoso, que pudo haberle causado la muerte.

Por lo que respecta al cáncer en el antiguo Perú es muy posible que este mal fuera endémico en el pasado y confirmaría que el ciclo de vida del yunga era corto, sin embargo, debido a las pocas investigaciones y hallazgos de individuos con este mal, un estudio mucho más profundo podría confirmar o refutar esta hipótesis planteada.

\section{Agradecimientos}

Queremos agradecer a la Lic. Carmen Gabe, directora del proyecto, quien nos concedió el permiso y apoyo para la investigación, así mismo a los arqueólogos Miguel Pazos, Genaro Barr y Odon Rosales, al igual que los bachilleres Marlit Gamarra, Rosario Arellano y Rossmery Roque por su apoyo durante la etapa de análisis. 


\section{BiBLIOGRAFÍA}

ALARCÓN, Pedro

1971 Tres fases técnico-constructivas en la huaca san Marcos. Tesis de Bachillerato en arqueología. UNMSM. Lima

ALLISON, Marvin, MENDOZA, Daniel y PEZZIA, Alejandro.

1973 "Documentation of a case of Tuberculosis in Pre-Columbian America". American Review of Respiratory Diseases N 107: pp. 985-991.

ALLISON, Marvin; LINDBERG, Lawrence; SANTORO, Calogero y FOCACCI, Guillermo

1981 “Tatuajes y Pintura corporal de los indígenas Precolombinos de Perú y Chile” Chungará N 7. Tarapacá. pp. 218-237.

ALTAMIRANO, Alfredo

2000 Comprometiendo la estructura osteo-facial de las poblaciones humanas del Antiguo Perú por la Leishmaniasis Tegumentaria de forma mucosa. Tesis de doctorado en ciencias. Fiocruz, Rio de Janeiro.

ALTAMIRANO, Alfredo y BUENO, Alberto

2013 "Un caso de cáncer metastásico en Zapallal a fines del Horizonte Medio (1100-1200), valle del Chillón, Perú". Investigaciones Sociales Vol. 17 N 30. Lima. pp. 91-104.

ALTAMIRANO, Alfredo; MARZOCHI, Mauro; MOREIRA, João; SCHUBACH, Armando y MARZOCHI, Keyla

2003 "Sobre a origem e dispersão das leishmanioses cutânea e mucosa com base em fontes históricas pré e póscolombianas”. História, Ciências, Saúde. Manguinhos. Vol. 10(3): 853-82. Rio de Janeiro.

ANDERSON, Trevor, WAKELY, Jennifer y CARTER, Adrian

1992 "Medieval example of Metastatic carcinoma: a dry bone, radiological and SEM studies". American Journal of Physical Anthropology $\mathrm{N}^{\circ}$ 89. pp. 309-23.

ANTÚNEZ DE MAYOLO, Santiago

1981. La nutrición en el antiguo Perú. Oficina Numismática. Banco Central de Reserva del Perú, Lima. AUFDERHEIDE, Arthur y RODRIGUEZ-MARTIN, Conrado

1998 Human Paleopathology. The Cambridge Encyclopedia. Cambridge University Press. UK.

BARAYBAR, Juan y SHIMADA, Izumi

1993 "A possible case of carcinoma metastatic in a middle sican burial from Batan Grande, Peru". International Journal of Osteoarchaeology $\mathrm{N}^{\circ} 3$. pp. 129-35.

BELCORE, Martha

1970 “Ídolo de Cerámica encontrada en la Huaca dieciocho (Fundo Pando-Lima)". Boletín del Seminario de Arqueología PUCP № 8. pp. 159-160. Lima.

BROTHWELL, Don

1967 “The evidence for neoplasms". En Disease in Antiquity. Editor Don Brothwell y A Sandison. Springfield.

BUIKSTRA, Jane

1980 "Precolumbian tuberculosis in the Americas". Northwestern University Archaeology Program Science Pap. № 1-6.

CALANCHA, Antonio

1639 Crónica moralizadora del orden de San Agustín en el Perú con sucesos ejemplares en esta monarquía. Pedro Lacavallería, Barcelona.

CANZIANI, José

1987 “Análisis del complejo urbano Maranga-Chayavilca”. Gaceta Arqueológica Andina № 14. Lima. pp. 10-17. 
Arelí Sullca, Johnny Taira y Alfredo Altamirano / El Tejedor: Un caso de cáncer metastásico en la Huaca Potosí...

2008 Ciudad y Territorio en los Andes: Contribuciones a la historia del urbanismo prehispánico" PUCP. Lima.

CARBONEL, Dayana

2013. Análisis Bioarqueológico de dos entierros humanos del sector j-12 de Huallamarca, valle del Rímac. Trabajo de investigación para optar el título de licenciatura. Universidad Nacional Federico Villarreal. Lima.

CARRIÓN, Lucénida y ESPINOZA, Pedro

2007a “Arquitectura, Cronología y función en la muralla 55E del complejo Arqueológico Maranga". Cuaderno de Investigaciones del Museo de sitio Ernst W. Middendorf № 1. Lima. pp. 33-66.

$2007 b$ "Investigaciones en la Huaca San Miguel, Complejo Arqueológico Maranga". Cuaderno de Investigaciones del Museo de sitio Ernst W. Middendorf № 1. Lima. pp. 67-115.

CCACHURA, Iván

2010 Secuencia de ocupación en el sitio Arqueológico № 18 del complejo urbano Maranga, en el valle bajo del rio Rímac. Tesis de Licenciatura. UNFV. Lima

CHAN, Keith.

2011 Life in the Late Intermediate Period at Armatambo, Perú. University of Missouri. Columbia.

DULANTO, Jalh

2002. "Pampa Chica: Practicas de culto a los ancestros en la costa Central del Perú". Gaceta Arqueologica Andina № 26. Lima. pp. 37-67.

ESPINOZA, Pedro

2010 "Arquitectura y procesos sociales tardíos en Maranga, valle bajo del Rímac, Lima”. Arqueología en el Perú: Nuevos aportes para el estudio de las sociedades andinas prehispánicas; Editores Rubén Romero Velarde y Trine Pavel Svendsen, UNFV. Lima.

ESPINOZA, Waldemar

1990 Los Incas. Economía, Sociedad y Estado en la era del Tahuantinsuyo. Amaru Editores. Lima.

FUNG, Rosa

2004 Quehaceres de la Arqueología Peruana. UNMSM. Lima

GABE, Carmen

2004 Informe del proyecto "Excavación con fines de consolidación, conservación, mantenimiento y Puesta en Valor en el Complejo Arqueológico Pando: Potosí, Miguel Grau, Aramburu. Distrito de San Miguel, Provincia de Lima". Lima.

HUTCHINSON, Thomas

1873 Two years in Peru, with exploration of its antiquities. Sampson Low. London

JAIME, Cecilia

1999 "Investigaciones en la huaca de San Marcos". Revista del Instituto de Investigaciones Histórico Sociales № 3 (III). Lima. pp. 65-91.

JIJÓN Y CAAMAÑO, Jacinto

1949 Maranga. Contribuciones al conocimiento de los aborígenes del Valle del Rímac, Perú. La Prensa Católica. Quito

HRDLICKA, Alex

1914 "Anthropological work in Peru in 1913, with notes on pathology of the ancient peruvians". Smithsonian Miscellaneous Collections $\mathrm{N}^{\circ} 61$. Washington DC. pp. 57-59.

1952 Practical Anthropometry. The Wistar Institute of Anatomy and Biology. Philadelphia.

HORKHEIMER, Hans

1973 La alimentación y la obtención de alimentos en elPerú Prehispánico. UNMSM. Lima. 
HOOTON, Earnest

1930 The Indians of Pecos Pueblo: a study of their skeletal remains. Yale University Press.

KAULICKE, Peter

1997 Contextos Funerarios de Ancón. Esbozo de una síntesis analítica. Fondo Editorial Pontificia Universidad Católica del Perú. Lima

KROEBER, Alfred

1954 “Proto-Lima. A middle Period culture of Perú". Fieldiana Anthropology № 40, (1). Chicago. pp. $1-125$.

LASTRES, Juan

1943 “Representaciones patológicas en la cerámica peruana”. Revista del Museo Nacional Tomo 2. Lima.

1951 “La Medicina en la época Inca”. Historia de la Medicina Peruana, tomo V (1). Lima.

LASTRES, Juan y CABIESES, Fernando

1959 “La Trepanación del cráneo en el Antiguo Perú". Anales de la Facultad de Medicina N 42 (3). Lima. pp. 258-320.

LOMBARDI, Guido

1994 Detección de Micobacterium tuberculosis en una momia de la cultura Nasca con mal de Pott. Premio anual de Medicina 1993. "Francisco Tejada y Semiramis Reategui". Lima.

LÓPEZ-DURÁN, Luis

1995 Traumatología y ortopedia. Madrid

LUMBRERAS, Luis

2011 Jacinto Jijón y Caamaño. Estudios sobre Lima prehispánica: Maranga. FONSAL. Quito.

MACCURDY, George

1923 "Human skeletal remains from the highlands of Peru". American Journal of Physical Anthropo$\log \mathrm{N}^{\circ}$ 6. pp. 217-329.

MACK KAY, Martin y SANTA CRUZ, Raphael

2000 “Las excavaciones del Proyecto Arqueológico huaca 20 (1999 y 2001)”. Boletín de Arqueología PUCP № 4. Lima. pp. 583-595.

MANCHESTER, Keith

1983 "Secondary cancer in an anglo-saxon female". Journal of Archaeological Science N¹0. pp. 47582.

MANRIQUE, Patricia

2011 "Arquitecturay contextos funerarios Limaenlalagunarecreativa delParquedelas Leyendas". Boletín del Museo de sitio Ernst W. Middendorf №10. Lima. 4-9.

2012 “Arquitectura y secuencia cultural prehispánica en huaca 43, Complejo Arqueológico Maranga”. Boletín del Museo de sitio Ernst W. Middendorf № 11. Lima. pp. 4-9.

MIDDENDORF, Ernst

1973 [1894] Perú. Observacionesyestudios del paísy sus habitantes duranteuna permanecía de 25 años. Tomo II: La Costa. UNMSM. Lima

MOODIE, Roy

1923 Paleopathology. An introduction to the study of ancient evidences of Disease. University of Illinois Press. Illinois

1926 "Tumors of the head among the pre-columbian Peruvians". Annals of medical History N 8. pp. 394-412. 
Arelí Sullca, Johnny Taira y Alfredo Altamirano / El Tejedor: Un caso de cáncer metastásico en la Huaca Potosí...

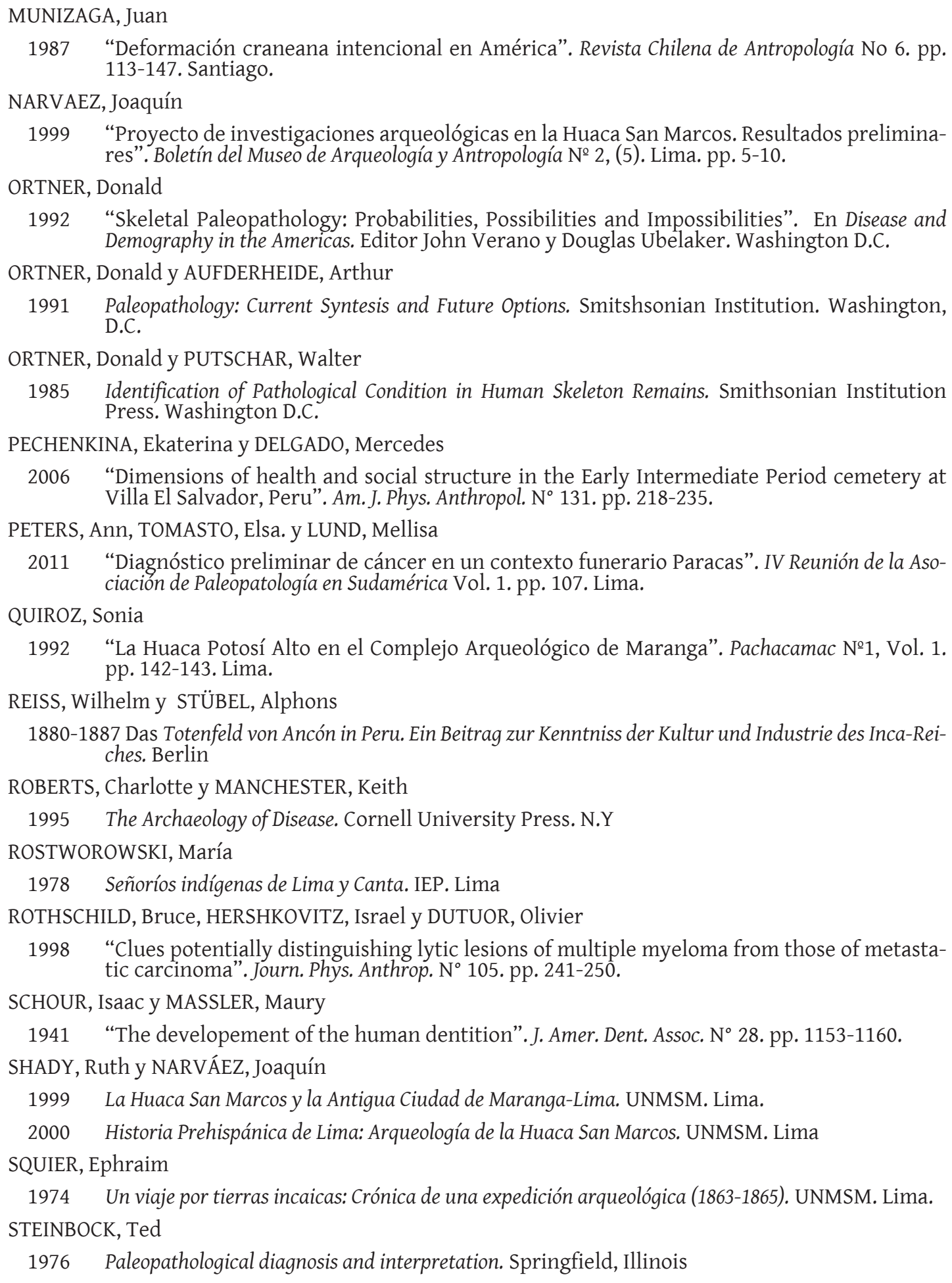

2006 "Dimensions of health and social structure in the Early Intermediate Period cemetery at Villa El Salvador, Peru". Am. J. Phys. Anthropol. N 131. pp. 218-235.

PETERS, Ann, TOMASTO, Elsa. y LUND, Mellisa

2011 "Diagnóstico preliminar de cáncer en un contexto funerario Paracas". IV Reunión de la Asociacion de Paleopatología en Sudamérica Vol. 1. pp. 107. Lima.

QUIROZ, Sonia

1992 “La Huaca Potosí Alto en el Complejo Arqueológico de Maranga". Pachacamac №1, Vol. 1. pp. 142-143. Lima.

REISS, Wilhelm y STÜBEL, Alphons

1880-1887 Das Totenfeld von Ancón in Peru. Ein Beitrag zur Kenntniss der Kultur und Industrie des Inca-Reiches. Berlin

ROBERTS, Charlotte y MANCHESTER, Keith

1995 The Archaeology of Disease. Cornell University Press. N.Y

ROSTWOROWSKI, María

1978 Señoríos indígenas de Lima y Canta. IEP. Lima

ROTHSCHILD, Bruce, HERSHKOVITZ, Israel y DUTUOR, Olivier

1998 "Clues potentially distinguishing lytic lesions of multiple myeloma from those of metastatic carcinoma". Journ. Phys. Anthrop. No 105. pp. 241-250.

SCHOUR, Isaac y MASSLER, Maury

1941 “The developement of the human dentition”. J. Amer. Dent. Assoc. N² 28. pp. 1153-1160.

SHADY, Ruth y NARVÁEZ, Joaquín

1999 La Huaca San Marcos y la Antigua Ciudad de Maranga-Lima. UNMSM. Lima.

2000 Historia Prehispánica de Lima: Arqueología de la Huaca San Marcos. UNMSM. Lima

SQUIER, Ephraim

1974 Un viaje por tierras incaicas: Crónica de una expedición arqueológica (1863-1865). UNMSM. Lima.

STEINBOCK, Ted

1976 Paleopathological diagnosis and interpretation. Springfield, Illinois 


\section{STROUHAL, Eugen}

1991 "Myeloma multiple versus osteolytic metastatic carcinoma: Differential diagnosis in dry bones". International Journal of Osteoarchaeology 1. pp. 219-24.

SULLCA, Areli y TAIRA, Johnny

2014 "El tejedor de Potosí, Análisis bioarqueológico de un fardo Maranga" Actas y Ponencias XXII CONEAR. Ayacucho

TAIRA, Johnny y SULLCA, Areli

2014 "Hallazgo de una puerta en la Huaca Potosí, Maranga". Arqueología y sociedad N² 27. Lima.

TELLO, Julio

1908 La antigüedad de la sífilis en el Perú. Tesis Facultad de Medicina Humana. UNMSM. Lima.

1931 “Un modelo de escenografía plástica en el arte antiguo peruano". Wira Kocha Vol. 1, N¹. pp. 89-112. Lima

1967 "La simbología en el arte nazca". Revista del Museo Nacional. Lima.

1999 Arqueología del valle de Lima. Cuadernos de investigación del archivo Tello 1. UNMSM. Lima.

TELLO, Julio y WILLIAMS, Herbert

1930 “An ancient syphilis skull from Paracas in Peru”. Annals of medical history Vol.1 (2) № 5. pp. 515-529. New York.

THILLAUD, Pierre

1996 "Paléopathologie humaine". Sceaux Cedex: Kronos.

TKOCZ, Izabella y BIERRING, Franz

1984 "A medieval case of metastasizing carcinoma with multiple osteosclerotic bone lesions". American Journal of Physical Anthropology $\mathrm{N}^{\circ}$ 65. pp. 373-80.

URTEAGA, Oscar y PACK, George

1966 "On the antiquity of melanoma". Cancer N 19. pp. 607-10.

VERANO, John y LOMBARDI, Guido

1999 "Paleopatología en Sudamérica Andina”. Bulletin de l'Institut français d'études andines 28(2). pp. 91-121.

VILLAR CORDOBA, Pedro

1935 Arqueología del Departamento de Lima. Municipalidad de Lima. Lima.

WALDRON, Tony

1987 “Lytic lesions in a skull: a problem in diagnosis". Journal of Paleopathology N 1 (1). pp. 5-14. WEISS, Pedro

1961 Osteología Cultural. 2da parte: Practicas Cefálicas. Fondo Editorial Universidad Nacional Mayor de San Marcos. Lima.

1970 Introducción a la Paleopatología Americana. Texto de Patologí. Editorial Fournier, México D.F.

1984 "Paleopatología Americana". Boletín de Lima 33. Lima. pp. 17-52.

2000 Pedro Weiss Harvey: Su obra científica.2 Tomos. Fondo Editorial Asociación de Médicos Cesantes y Jubilados del Ministerio de Salud. Lima.

ZIMMERMAN, Michael y KELLEY, Marc

1982 Atlas of Human Paleopathology. Praeger Publishers CBS Educational and Professional Publishing a Division of CBS Inc. New York. 